\title{
Permainan Edukatif dan Kreatif Ular Tangga Menurunkan Dampak Negatif Gadget pada Anak
}

\author{
Erna Julianti ${ }^{1}$, Elni $^{2}$ \\ ${ }^{1,2}$ Akademi Keperawatan Pangkalpinang \\ Email:erna.julianti08@gmail.com
}

Submitted : 05/11/2020

Accepted: 19/11/2020

Published: 11/01/2021

\begin{abstract}
The gadgetis one of the current technology development used by all groups of people, including children. School-age children (7-11 years old) use a gadget since their parents are busy to work and the price of the gadget is getting cheaper due to market competition. The frequently occurred problem these days is that children often use their gadgets to play games more than studying or playing outside their house with their same-age friends. When the children at home, it gets difficult to communicate with them, they are being indifferent and do not respond to what their parents say. Besides, the gadget also causes a problem in children's motor development and eye health. This community service was conducted at a public elementary school, namely SD Negeri 21 Pangkal pinang. It was conducted in December 2019. The target was elementary level students. The method of this community service was done through an educative and creative, namely snake and ladder. The result showed a significant average value between the knowledge before (pre-test) and after the treatment (post-test) by using the educative and creative, namely snake and ladder. There was an increase in the average value of children's knowledge after playing snake and ladder game by 18.69. It is expected that there is supervision from the family when the students use a gadget. Family is also expected to explain the information obtained by the children from the Internet and also give the children a duration when playing games using a gadget to prevent them from its negative impacts, such as vision problems.
\end{abstract}

Keywords: gadget, playing, snake and ladder game

\begin{abstract}
Abstrak
Gadget merupakan salah satu perkembangan teknologi masa kini yang digunakan oleh semua kalangan termasuk anak-anak. Anak usia sekolah (7-11 tahun) menggunakan gadget karena faktor orang tua yang sibuk bekerja dan harga gadget yang semakin murah akibat persaingan dipasaran. Permaslahan yang sering terjadi saat ini adalah Anak-anak lebih sering menggunakan gadgetnya untuk bermain game daripada untuk belajar ataupun bemain di luar rumah dengan teman-teman seusianya. Ketika dirumah anak menjadi susah diajak berkomunikasi, tidak peduli dan kurang berespon pada saat orang tua mengajaknya berbicara. Selain itu, gadget juga berdampak pada gangguan perkembangan motorik dan kesehatan mata anak. Kegiatan Pengabdian kepada masyarakat ini dilaksankan di SD Negeri 21 Pangkalpinang. Waktu pelaksanaan pada bulan Desember 2019. Sasaran adalah anak sekolah dasar. Metode pengabdian masyarakat melalui permainan edukatif dan kreatif ular tangga. Hasil yang diperoleh adalah terdapat perbedaan yang signifikan nilai rata-rata antara pengetahuan sebelum (pre test) dan setelah (post test) melakukan permaian edukatif dan kreatif ular tangga. Ada kenaikan nilai rata-rata pengetahuan anak setelah bermain ular tangga sebesar 18,69. Diharapan adanya pengawasan dari keluarga saat siswa tersebut menggunakan gadget. Keluarga juga diharapkan memberikan penjelasan terhadap informasi yang didapatkan anak dari internet dan juga memberikan batasan waktu bermain gadget bagi anak agar terhindar dari dampak negatif gadget seperti kerusakan kesehatan mata.
\end{abstract}

Kata kunci: gadget, bermain, ular tangga 


\section{PENDAHULUAN}

Gadget merupakan salah satu perkembangan teknologi masa kini yang digunakan oleh semua kalangan termasuk anak-anak. Anak usia sekolah (7-11 tahun) menggunakan gadget karena faktor orang tua yang sibuk bekerja dan harga gadget yang semakin murah akibat persaingan dipasaran. Aplikasi-aplikasi yang terdapat pada gadget tersebut bukan hanya aplikasi tentang pembelajaran mengenal huruf atau gambar serta informasi pengetahuan, tetapi terdapat aplikasi hiburan, seperti sosial media, video, gambar bahkan video game. Anak-anak akan lebih sering menggunakan gadgetnya untuk bermain game daripada untuk belajar ataupun bemain di luar rumah dengan teman-teman seusianya (Nurrachmawati, 2014).

Dallea, Mutalibb, Saadb, Ayubc, Wahabc, dan Nasrallad mengatakan bahwa sebagai efek dari media elektronik, anakanak memiliki sedikit ruang untuk bermain di lingkungan luar rumah. Berdasarkan beberapa penelitian, anak-anak berusia 0-2 tahun tidak boleh terpapar gadget, anak usia 3-5 tahun dibatasi hanya 1 jam per hari, dan 2 jam per hari untuk anak-anak berusia 6-18 tahun. Namun fakta di lapangan menunjukkan bahwa banyak anak menggunakan gadget 4-5 kali lebih banyak dari jumlah yang direkomendasikan (Suhana, 2017). Data dari KOMINFO tahun 2014, tingkat penggunaan gadget di Indonesia sangat tinggi. Berdasarkan survei, ditemukan bahwa 98 persen anakanak dan remaja di Indonesia mengetahui internet dan 79,5 persen diantaranya adalah pengguna internet dan gadget. Penggunaan gadget pada anak sangat tidak disarankan karena dapat mengganggu proses tumbuh kembangnya.

Hasil penelitian Sapardi (2018) menunjukan sejak menggunakan gadget, ketika dirumah anak menjadi susah diajak berkomunikasi, tidak peduli dan kurang berespon pada saat orang tua mengajaknya berbicara. Selain itu, gadget juga berdampak pada perkembangan motorik anak. Penelitian yang dilakukan oleh Fanny et al (2014) menyatakan salah satu faktor yang mempengaruhi perkembangan motorik siswa sekolah dasar adalah lama anak mengenal gadget dan lama penggunaan gadget setiap harinya.

Anak yang menghabiskan waktunya dengan gadget tanpa memperhatikan kecerahan layar gadget, efek radiasi gadget, dan jarak layar dari mata anak juga dapat mempengaruhi kesehatan mata anak. Selain itu, anak yang melihat layar elektronik terus-menerus dalam waktu lama menyebabkan iritasi mata, stres pada fungsi penglihatan, Penurunan tajam penglihatan dan miopi (Sundus, 2018). Stres pada otot akomodasi dapat terjadi pada saat seseorang berupaya untuk melihat pada objek berukuran kecil dan pada jarak yang dekat dalam waktu yang lama. Pada kondisi demikian, otot-otot mata akan bekerja secara terus menerus dan lebih dipaksakan. Ketegangan otot-otot pengakomodasi (otototot siliar) makin besar sehingga terjadi peningkatan asam laktat dan sebagai akibatnya terjadi kelelahan mata, stress pada retina dapat terjadi bila terdapat kontras yang berlebihan dalam lapangan penglihatan dan waktu pengamatan yang cukup lama (Ilyas, 2004). Hasil penelitian Ernawati, Budiharto, dan Winarianti (2015) juga menyatakan bahwa ada pengaruh antra posisi dan intensitas pencahayaan menggunakan gadget terhadap penurunan tajam penglihatan pada anak. Semakin bertambahnya penurunan tajam penglihatan pada anak, maka akan meningkatkan berbagai resiko komplikasi kebutaan, seperti glukoma dan abrasi retina (Tiharyo et al., 2008).

Perawat sebagai tenaga kesehatan bertanggung jawab dalam menurunkan dampak negatif gadget pada anak-anak, khususnya siswa sekolah.Oleh karena itu, perlu adanya kegiatan pengabdian kepada masyarakat melalui permainan edukatif dan kreatif ular tangga pada anak prasekolah 
tentang dampak gadget bagi anak sehingga dapat menurunkan dampak gadget pada anak

\section{TARGET DAN LUARAN}

Target dilaksanakannya kegiatan pengabdian kepada masyarakat dalam menurunkan dampak Gadget melalui Permainan edukatif dan Kreatif di SD N 21 Pangkalpinang" maka diharapkan dapat menurunkan dampak negatif gadget pada anak dan meningkatkan kesehatan serta tumbuh kembang anak menjadi optimal melalui permainan edukatif dan kreatif ular tanggatentang dampak gadget.

Luaran kegiatan pengabdian ini adalah ada peningkatan pengetahuan anak tentang dampak gadget dan juaga meningkatkan antusias anak dalam bermain permaina edukatif dan kreatif ular tangga. Hasil kegiatan bermain ular tangga ini dapat meningkatakn perkembangan anak dan menurunkan dampak negatif gadget pada anak serta juga dipublikasikan dalam bentuk jurnal ilmiah nasional sehingga dapat diakses oleh masyarakat.

\section{METODE PELAKSANAAN}

Kegiatan pengabdian masyarakat ini merupakan salah satu tugas tridarma perguruan tinggi yang dilakukan oleh dosen bersama mahasiswa Akper Pangkalpinnag untuk menurunkan dampak negatif gadget pada anak sekolah. Kegiatan yang dilakukan yaitu bermain ular tangga tentang dampak gadget. Kegiatan ini dilaksanakan di SD Negeri 21 Pangkalpinang, pada hari Senin, tanggal 16 Desember 2019, pukul 09.00 WIB sampai dengan selesai.

Tahapan kegiatan pegabdian kepada masyarakat antara lain:

1. Tim Pelaksana meminta izin dan menjelaskan kepada Kepala Sekolah dan guru kelas melaksanakan kegiatan pengmas tentang dampak gadget melalui permainan ular tangga. Semua siswa kelas 3 dikumpulkan dalam satu ruangan. Kegiatan diawali dengan tim memperkenalkan diri kepada peserta pengmas. Ketua pelaksana menjelaskan maksud dan tujuan kegiatan kepada peserta.

2. Setelah perkenalan, Ketua pelaksana menjelaskan kepada peserta cara pengisian kuesioner. Dua orang mahasiswa membagikan kuesioner pretest kepada semua peserta. Setelah itu, peserta mengisi kuesioner pretest. Tujuan pretest ini yaitu untuk mengetahui pengetahuan awal peserta tentang dampak gadget.

3. Ketua pelaksana menjelaskan aturan main dalam permainan ular tangga terlebih dahulu kepada peserta. Ketua pelaksana juga bertugas memfasilitasi dan mengatur permainan ular tangga. Setelah itu, tim menunjuk 4 orang peserta untuk bermain ular tangga. Masing-masing bermain ular tangga secara bergantian. Peserta melempar dadu dan melangkah menuju kotak sesuai dengan jumlah dadu. Apabila berada di kotak yang adanya tangga, maka peserta berhak naik ke kotak yang di tuju. Dan apabila peserta berada di kotak dengan gambar kepala ular, maka peserta harus turun mengikuti ekor ular. Perbedaanya, pada media permainan ular tangga ini hampir di setiap kotak memiliki instruksi tersendiri. Setiap peserta wajib membaca dengan keras instruksi yang ada didalam kotak dan anggota pelaksana menjelaskan kepada semua peserta instruksi didalam kotak (dampak positif atau dampak negatif dari Gadget).

4. Setelah melakukan permainan ular tangga, peserta dibagikan kembali kuesioner postest oleh tim pelasana (mahasiswa). Postes ini bertujuan mengetahui peningkatan pengetahuan peserta setelah diberikan informasi mengenai dampak gadget 


\section{HASIL DAN PEMBAHASAN}

Gambaran pengetahuan siswa tentang dampak gadget sebelum dan setelah melakukan permainan ular tangga

Tabel 1 Distribusi pengetahuan siswa tentang dampak gadget $(n=38)$

\begin{tabular}{ccccc}
\hline $\begin{array}{c}\text { Variabel } \\
\text { Pengetahuan }\end{array}$ & $\begin{array}{c}\text { Mean } \\
\text { (rata- } \\
\text { rata) }\end{array}$ & $\begin{array}{c}\text { Standar } \\
\text { Deviasi } \\
\text { (SD) }\end{array}$ & $\begin{array}{c}\text { CI } \\
95 \%\end{array}$ & $\begin{array}{c}P \\
\text { Value }\end{array}$ \\
\hline Pretest & 68,42 & 14,98 & $63,5-$ & 0,0001 \\
& & & 73,5 & \\
Postest & 87,11 & 13,13 & $82,79-$ & \\
& & & 91,42 & \\
\hline
\end{tabular}

Berdasarkan tabel 1 didapatkan bahwa nilai rata-rata pengetahuan siswa sebelum melakukan permaianan ular tangga sebesar 68,42 dengan standar deviasi sebesar 14,98 sedangkan nilai rata-rata pengetahuan siswa setelah melakukan permainan ular tangga sebesar 87,11 dengan standar deviasi sebesar 13,13. Dapat disimpulkan bahawa terdapat perbedaan yang signifikan antara pengetahuan siswa sebelum dan setelah dilakukan permaian ular tangga dengan $\mathrm{p}$ value 0,0001 . Dan terjadi kenaikan nilai rata-rata pengetahuan sebesar 18,69.

Hasil kegiatan pengabdian masyarakat menunjukan bahawa terjadi peningkatan pengetahuan sebelum dan setelah diberikan permaian edukatif dan kreatif ular tangga. Media permainan ular tangga dipilih sebagai media pengabdian masyarakat karena permainan ular tangga merupakan salah satu cooperative play dan termasuk permainan tradisional yang murah, mudah dibuat, anak belajar bekerja sama dan berkompetisi sehat, membantu anak bersosialisasi dengan teman sebayanya serta bermain sambil belajar. Pemilihan media permainan ular tangga juga dipilih karena merupakan salah satu upaya untuk menghindari dampak negatif gadget yaitu dengan bermain di luar rumah atau melakukan aktivitas fisik. Salah satu starategi untuk perubahan perilaku adalah pemberian informasi guna meningkatkan pengetahuan sehingga timbul kesadaran yang pada akhirnya orang akan berperilaku sesuai dengan pengetahuannya tersebut. Salah satu upaya pemberian informasi yang dapat dilakukan adalah permainan edukatif dan kreatif ular tangga. Pengetahuan terjadi setelah seseorang melakukan penginderaan terhadap suatu objek atau stimulus (Notoatmodjo, 2012).

Sosialisasi melalui permainan ular tangga juga didasari teori pembelajaran yaitu social learning theory. Social learning theory merupakan teori yang menekankan pada komponen kognitif dari pikiran, pemahaman dan evaluasi (Bandura, 1977). Teori ini juga menyatakan individu belajar dari interaksi dengan orang lain dalam konteks sosial serta mengamati dan meniru prilaku orang lain. Proses belajar sosial terdiri dari 4 komponen yaitu attentional, retention, motor reproduction, dan motivational process (Gibson, 2004). Media pembelajaran yang menarik dan mudah dicontoh seperti media permaian ular tangga juga dapat meningkatkan proses atensi dan retensi pembelajaran siswa. Media pembelajaran yang digunakan didasarkan pada prinsip bahwa pengetahuan yang ada pada setiap manusia itu diterima atau ditangkap oleh panca indra, semakin banyak indra yang digunakan untuk menerima sesuatu, maka akan semakin jelas pengertian yang diperoleh. Sesuatu yang menimbulkan perhatian, akan memberikan pengertian baru bagi siswa dan meningkatakan pemahaman siswa tentang dampak dari gadget sehingga siswa membatasi untuk bermain gadget (Notoatmojo, 2010).

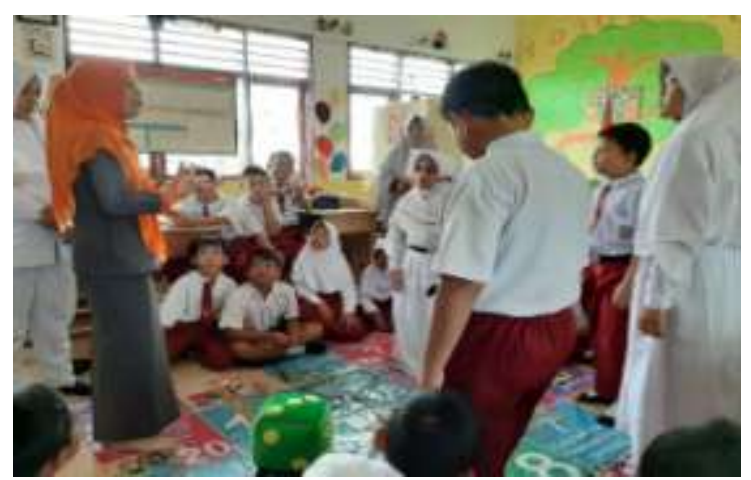


Gambar 1: menjelaskan aturan bermain ular tangga

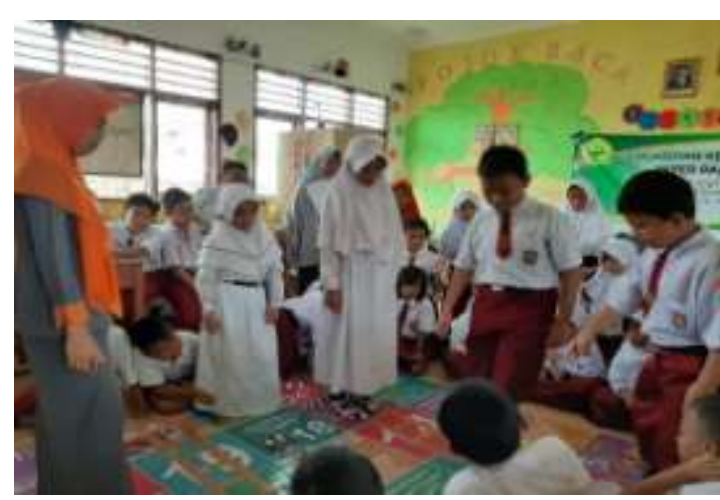

Gambar 2 peserta bermain ular tangga

\section{KESIMPULAN DAN SARAN}

\section{Kesimpulan}

Kegiatan pengabdian masyarakat berjalan dengan baik. Terlihat dari penerimaan pihak sekolah yang baik dan antusias dari siswa-siswa sekolah dasar tersebut dalam mengikuti kegiatan pengabdian masyarakat. Hasil kegiatan terdapat perbedaan yang signifikan nilai rata-rata antara pengetahuan sebelum (pretest) dan setelah (posttest) melakukan permaian edukatif dan kreatif ular tangga.

\section{Saran}

Diharapkan adanya pengawasan dari keluarga saat anaknya menggunakan gadget. Keluarga juga diharapkan memberikan penjelasan terhadap informasi yang didapatkan anak dari internet dan juga memberikan batasan waktu bermain gadget bagi anak agar terhindar dari dampak negatif gadget seperti kerusakan kesehatan mata dan lain-lain.

\section{DAFTAR PUSTAKA}

Bandura, A. (1977). Social Learning Theory. Englewood Cliff s, New Jersey: Prentice-Hall, Inc.

Ernawati, W. (2015). Pengaruh penggunaan gadget terhadap penurunan tajam penglihatan pada anak usia sekolah
(6-12 tahun) di SD Muhammadiyah 2 Pontianak Selatan. Jurnal Proners, 3(1).

Fanny, A. O., Tutut, J. P., Giyanti, 1. P., Alfisyahrina, H. \&Aandriana, y. (2014). Faktor Pengaruh Gadget Terhadap Kecerdasan Motorik Siswa SD Melalui Regresi Logistik Ordinal. Institut Teknologi Sepuluh Nopember Surabaya.

Gibson, S. K. (2004). Social learning (cognitive) theory and implications for human resource development. Advances in Developing Human Resources, 6(2), 193-210. Retrieved from https://search.proquest.com/docview/221 206794? accountid $=17242$

Ilyas, S. (2004). Ilmu Perawatan Mata. Jakarta: Sagung Seto.

Notoatmojo, S. (2010). Promosi kesehatan: Teori dan aplikasi. Edisi Revisi. Jakarta: Rineka Cipta

Nurrachmawati. (2014). Pengaruh sistem operasi mobile android pada anak usia dini. Jurnal pengaruh system operasi mobile android pada anak usia dini. Makasar: FT Universitas Hasanuddin.

Sapardi, V. S. (2018). Hubungan penggunaan gadget dengan perkembangan anak usia prasekolah di PAUD/TK Islam Budi Mulia. Menara Ilmu, 12(80).

Sundus, M. (2017). The Impact of using Gadgets on Children. Journal Depress Anxiety 7(1), 296. doi: 10.4172/2167-1044.1000296

Suhana, M. (2017). Influence of Gadget Usage on Children's Social-Emotional Development. In International Conference of Early Childhood Education . Atlantis Press.https://doi.org/10.2991/icece17.2018 .58

Tiharyo, I., Gunawan, W., \& Suhardjo. (2008). Pertambahan Miopia pada Anak Sekolah Dasar Daerah Perkotaan dan Pedesaan di Daerah Istimewa Yogyakarta. Jurnal Oftalmologi Indonesia, 6(2), 104-112 